\title{
REGIONAL MANPOWER PLANNING
}

\author{
G Erens, $\mathrm{P}$ Salemink and $\mathrm{C} A$ van der Merwe \\ Department of Quantitative Management \\ University of South Africa \\ P O Box 392 \\ Pretoria 0001 \\ South Africa
}

\section{Abstract}

Particular problems come to the fore when planning development at the regional level. These range from the complexities of the multifarious interactions between the sectoral and local components of the region to the necessity of achieving extensive participation of regional stakeholders in the planning process. In this paper a methodology for regional manpower planning is proposed. The methodology is designed to accommodate the full range of problems by applying a systems approach which is based on the disciplines of operations research and strategic planning.

\section{Introduction}

"A coherent development strategy for the Economic Community of Southern Africa should be directed at the development of the less developed areas in the subcontinent in a regional context" (Development Bank of SA [5], Preface). There are particular problems that arise when planning development at the regional level, not the least of which is the highly interactive flux of manpower between the different regions of Southern Africa. In this paper a methodology, which adopts a systems approach to manpower planning at a regional level, is proposed. This approach is based upon an integration of the modelling techniques of operations research with the facilitating techniques of strategic planning. 
In a generalized sense "manpower planning" refers to the matching of manpower requirements and resources, be it for a single organization or within a whole economy. In so far as it attempts to define strategies for providing appropriately trained manpower, manpower planning usually refers to the art of deducing future educational and training needs from estimates, or projections, of expected manpower patterns at some future date. Although, in this broad sense of matching requirements and resources, manpower planning is ostensibly a process which is independent of the level at which it is done, in fact this is not the case. To understand the differences which arise in practice it is necessary to define manpower planning more precisely. For this purpose the "Definitions and Typology for Manpower Planning" of Mangum and Snediker [12] serves to best elucidate these differences.

They firstly define manpower development:

"Manpower development refers to the enhancement of every human ability which contributes to effectiveness in the employment nexus. Manpower policy is a two-sided term encompassing all social decisions which deliberately affect:

(1) The use of people in labour markets as economic factors of production.

(2) The ability and opportunity for people to pursue remunerative and satisfying work careers in employment."

The manpower system can be thought of "as those forces in society which not only use people in productive ways but also create their productivity". It must, inter alia, recruit from the population pool, motivate and prepare for productive activity and create employment opportunities and match people to them, both temporally and spatially. "(Manpower) planning is a systematic way of thinking through and designing a system to do these things".

They go on to distinguish four major levels of manpower planning: 
Macro Manpower Planning - The point is that any economic planning at national level with improved employment as its primary goal can be viewed as manpower planning. Indeed many countries have specific departments, bureaux, commissions or other agencies with this brief, for example the National Commission for Manpower Policy in the USA (see reference [13]). A South African example of such planning is the projection of the graduate manpower needs of the country done by the Department of National Education (see reference [17]). For a review of the techniques used at this level see Beenstock [2], while a recent survey of current issues is given by Briggs [4].

Micro Manpower Planning - At the opposite end of the spectrum is manpower planning within organizations which has as basic purpose the presence of the right numbers of the right types of personnel in the right jobs at the right times. This is certainly the area of manpower planning that has received the most attention and which is the best developed. (See for example Burack and Mathys [3] and Grinold and Marshall [7]). It is, however, very specific and the furthest removed from the focus of this article.

Manpower Programme Planning - This has as its focus the employability and employment of those individuals who find it most difficult to compete successfully for the opportunities available in the job market. Much in-service training has as its aim the improvement of the employability, opportunities and incomes of the target group. (See for example the proceedings of the National Symposium on Manpower Development for the New South Africa [14], which was held in Pretoria during October 1991).

Labour Market Manpower Planning - In this case the emphasis is on a local labour market, that is on a geographical area or subregion which emcompasses the residences and work places of most workers within normal commuting patterns. To the extent that planning is hierarchical it should accord with the overall macro plan of the region or super region (ie country) of which it is part. It must incorporate and bring together both the supply of and the demand for labour. On the other hand it should encompass the necessary programme planning (referred to above) in order to achieve optimum employment patterns and social well-being. In fact it is at this level that Mangum and Snedeker's book [12] is directed. 
Regional manpower planning, as described in this article, lies somewhere between the first and last of the levels described above - that is between the macro and local levels, and, in addition, encompasses aspects of programme planning. It attempts to take the longer term view of the macro plan but is compounded by the complexities of the interaction of regional and national factors, as well as by the need for local detail. Since the supply and demand for manpower at a regional level are governed by a complex interplay of a host of factors, from demographics, through social and political considerations to various economic matters, regional manpower planning is necessarily a sophisticated process which can only be accomplished using the combined tools and techniques of several disciplines. In fact in order to properly do such planning the joint expertise of several experts with training from such disparate fields as the mathematical sciences, the economic and business sciences and the human sciences, must be applied to the problem.

\section{A Systems Approach to Regional Manpower Planning}

The traditional approach to manpower planning relies largely on mechanistic projections derived from available data. (See, for example, Youdi and Hinchliffe [18]). This is generally not the most effective means of forecasting. For, apart from the likely paucity or inadequacies of past data, there is the very real possibility that the results might be a perpetuation of past errors into the future. This does not mean that projections are to be avoided - in fact they are central to all manpower planning. They must, however, be used with great circumspection. On the other hand the more modern techniques of strategic planning, as developed for the business environment, can also contribute to an understanding of the complex interrelationships between the multitude of factors relevant to the formulation of a manpower plan. But these too cannot be applied in isolation. The point is that without some wider framework, within which projections and other assumptions or suggestions, can be tested for consistency, the whole planning process is likely to collapse into confusion. Such a framework can only be provided by a carefully conceived, constructed and tested "systems model". Operations Researchers generally are well-acquainted with systems modelling and in fact nowadays most standard texts on operations research include a chapter on the systems approach. 
For our purposes the most comprehensive description is that of Jenkins [9].

The systems approach recognizes the interdependency and interaction of the many complex factors. It clearly states the underlying assumptions which may then be subject to scrutiny. These assumptions are not only determined by the nature and extent of the problem but also by the particular perspective which is relevant. In practice this means that a number of interrelated sub-models have to be constructed which are bound together by an overall conceptual model, in order to achieve consistency. Thus separate sub-models must be used to examine the situation from the demographic, economic and social need perspectives. This need for the recognition of the interrelatedness of the various sub-systems pertaining to the development process has recently been emphasized by a number of authors. Most pertinent to this article are those of Mangum et al [11], Bandyopadhyay and Datta [1], Nkuhlu [15] and Farooq and Mackellar [6].

In addition to the sub-models it is important that, for a complex and expansive region as is the case with many of the economic/development regions in Southern Africa, regionalized modelling be performed. Thus, the overall model must be further regionalized into existing sub-regions. This is necessary for a variety of reasons. First, labour markets are by no means homogeneous. They are segmented by different variables and a clear understanding of spatial segmentation processes is necessary to arrive at an understanding of the macro-process. Unemployment in particular is uneventy distributed among sub-regions and individuals. A further reason is that geographical space proves to exert a frictional effect on labour market adjustment processes, which, if not properly accounted for, may lead to less efficient allocation of human resources. Lastly the issue of occupational mobility also has a strong influence on regional manpower issues, particularly as far as in- and out-migration patterns are concerned. The models of the sub-regions must then be integrated into a coherent model for the whole of the region under consideration. In this way a properly "layered" model is obtained so that it can adequately accommodate, and provide answers in respect of the sub-regions within a region. 
On the other hand regional modelling must also take place within the wider perspective of the larger system. In this case this means that the region cannot be viewed entirely in isolation but must be considered within the context of trends and developments in Southern Africa as a whole - at least to the extent that this is necessary. Without a systems model this perspective is very difficult, if not impossible, to achieve.

Furthermore, in the spirit of strategic planning, and in order to achieve maximal advantage from the information and insights provided by a systems model, a process of complete participation by all stakeholders, is required. (See King and Cleland [10]). This means that there must be interaction on a more or less continuous basis with, say, work groups representing the different sectoral and regional interest groups. This is important not only for the qualitative understanding that they can provide with regard to particular local considerations, but also because in the long run when it comes to the implementation of the plans devised this can only be achieved if there is commitment on the part of the stakeholders of the region.

\section{Overall Conceptual Model}

In figure 1 the overall conceptual model of the process leading to the formulation of an Overall Manpower Development Strategy for a specific economic/development region is depicted. This model is central to the methodology. Hence, on the one hand, it serves as the framework within which proposals are formulated and executed. Three phases of the methodology are also indicated in the figure, although strictly speaking they are not part of the model. On the other hand, and more importantly, it is the framework which, as explained above, is used for a systematic and consistent approach to manpower planning. Note that consistency implies, among other things, that due allowance must be made for the external environment, as indicated in the figure. The separate sub-models are developed as alternative approaches in Halstead [3] but are not integrated into a systems model. In one way or another they are all tried and tested models since they have all been used for manpower planning from different perspectives (See again Beenstock [2] and Youdi and Hinchliffe [18], and also Smith [16] for examples of their use in isolation). Venter [17], on the other hand, successfully applied them in concert to the closed system of the Southern African Constellation as a whole but restricted to only high level 


\section{Phase 1}

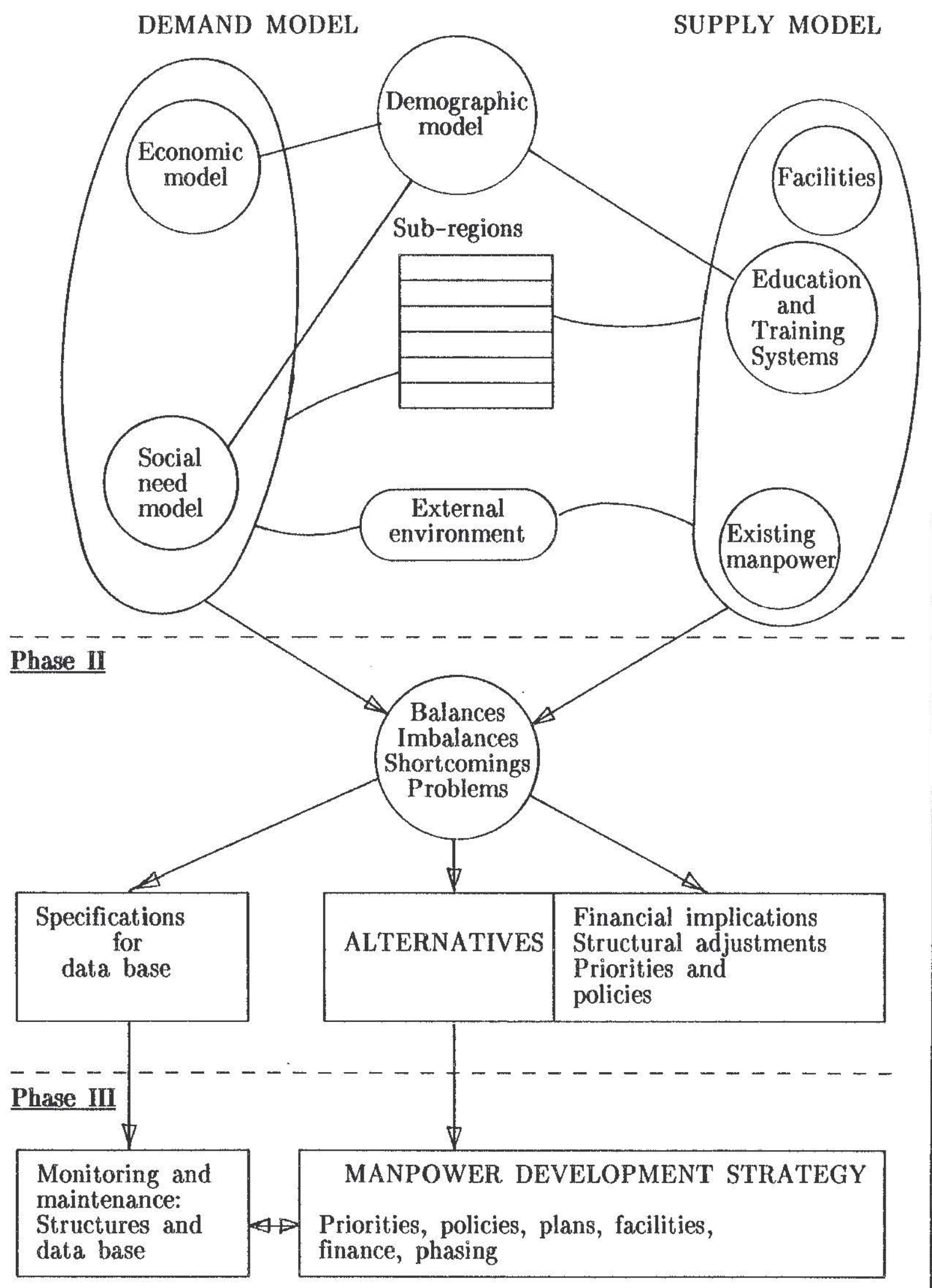

Figure 1. Overall Conceptual Model for Manpower Planning 
(graduate and diplomate) manpower and without attention to regional detail. This article goes further and Venter's model is extended to include all manpower levels as well as the details pertinent to a region within the wider system. In particular this means that the system under consideration is no longer closed but the interaction with the wider system must be carefully considered. The most important aspect of this interaction is the flux across the boundry of the region and considerable attention is given to this complication (in paragraph 5.4 below).

A brief description of the salient features of the conceptual model follows. This serves to give a succinct overview which will enable others to judge the cardinal issues in manpower planning, and so to critically review proposals. A more detailed description of the process and the systems model follows in the rest of the paper.

Phase I : Situation Analysis and Model Development

This phase involves the "Model Formulation and Development" and precedes the final situation analysis which is an integral part of the modelling process. It is the major section of the study since it involves a detailed analysis of the two cardinal aspects of manpower planning, namely demand and supply, taking into account the underlying demographics. Prior to this an analysis of the current mission, objectives and goals for manpower development must be undertaken and an understanding reached on the levels and types of manpower that are to be included in the study.

As is indicated in the figure the current demand is analysed, and the future demand is estimated, on the basis of three sub-models: one each for economic and social-need considerations, and using the output from the demographic model as needed. A complicating factor is the flux of manpower across the boundary of the region into neighbouring regions and further afield. This too must be adequately accounted for in the model. Final manpower forecasts are deduced by a synthesis of the results obtained using these models. 
Supply, in turn, is based upon outputs generated by the demographic model and is analysed and forecast using a model which describes attrition of the existing labour force as well as additions to it, both from the education and training systems and from without. Of course the production of the former system is determined by the availability and utilisation of teaching and training resources and facilities. The inherent variability in these factors, among other, leads to the generation of possible alternatives to be explored in phase II. It must be stressed that supply and demand continually interact, and a host of external factors influence the intensity, nature and extent of this interaction. (These remarks serve, to illustrate the interrelated nature of all phases of the project and to underline the emphasis on a systematic approach to it.)

As previously mentioned, a facet of the systems model which must be incorporated in the case of most regions is that it must be possible to identify sub-regional components. This implies that the model must be properly "layered" which in turn is best achieved by the use of a well-constructed underlying regionalized data base model. An additional advantage of such a "layered model" is that it will facilitate an inquiry system which will be especially suitable for on-going planning once the basic strategic plan is complete. Furthermore it should facilitate the later integration of other sub-regions and even regions. On the other hand it would also lend itself to the further sub-division of sub-regions at a later stage.

Phase II : Development of Strategic Alternatives

Once the basic models for demand and supply have been accepted they can be used to perform a sensitivity analysis for each of these functions. More specifically the demand is dependent on a number of underlying assumptions, and by varying given parameters, for example the growth in GDP per sector, the resultant variability in the corresponding demand can be obtained. As explained above the supply side is also not without inherent variability. Particular attention must be given to those parameters which can be relatively easily manipulated by the application of government policies. Examples of such policies are job creation programmes, sectoral 
development policies, etc. On the other hand for parameters which are outside the control of government, in each case an estimate must be made of the most likely value as well as possible upper and lower bounds on its value. With this information in hand an attempt can be made to balance demand and supply. By choosing a number of disparate parameter sets a range of alternatives, corresponding to different possible options, policies and, perhaps most importantly, different levels of funding for education and training, can be put forward for consideration by the authorities.

Phase III : Formulation of an Overall Manpower Development Strategy

From the array of alternatives one will have to be selected by the relevant authority as the basis for an Overall Manpower Development Strategy.

Once this has been done the detailed policies and steps necessary to implement the strategy will have to be formulated, along with structures for the monitoring and maintenance thereof. (This implies the creation and maintenance of a data base specifically for this purpose.)

It must be emphasized that if it becomes apparent, even at this late stage, that the set of alternatives are inadequate then it is possible to rerun the basic model (of phase I) in order to determine whether other alternatives are not perhaps available (possibly in the light of new insights which have come to the fore in the decision process).

\section{The Process}

In the introduction above it was emphasized that a systems approach like the one envisaged here cannot be undertaken by a team of experts alone, no matter how great their expertise - the stakeholders of the region under consideration must be fully involved in all phases of the investigation and subsequent development of the strategy. This is necessary in order to not only ensure the relevancy of the plans to the region but is also essential if they are ultimately to be implemented with success. Such participation is best achieved by the constitution of working groups representing the various sectoral and governmental interest groups of the region. In addition the 
commissioning authority has to ensure that the consultants contracted are indeed following their brief, not only in terms of financial agreements and time constraints but also in respect of deliverables. This control can be achieved in a number of ways but from the perspective of a systems approach it is best done via a properly constituted "steering committee", appointed by and reporting to the commissioning authority, but with members representing the major interest groups of the region. Thus the process is one of on-going interaction between a team of experts, which must have a sufficiently wide spectrum of expertise, the working groups and the steering committee. Typically progress reports will be presented to the latter at preset deadlines, at which times they will then decide on the further course of action. The process is depicted in figure 2 below, as three parallel sequences of activities in constant interaction with each other. (In reality it is, of course, even more complex as a result of the many vital informal relationships that develop between the different persons and parties involved in the process). In this way the quantitative perspectives of systems modelling are integrated with the qualitative understanding which follows from strategic planning sessions, resulting in a product which is superior to one which would be obtained if either procedure is used alone.

\section{Model Formulation and Development}

The rational and precedents for the model are described in section 3 above.

There are four main components to the systems model - sub-models for demographics, demand and supply of manpower, and a model for the flux of manpower across the boundaries of the region.

\subsection{An Extended Demographic Model}

As its name suggests this is a model for forecasting population growth in the first place. It is, however, more than just a simple demographic model since it must forecast educational and economic profiles of the population as well as the usual age profiles. It provides essential input to both the demand and supply models and is in fact intricately linked to both. In 


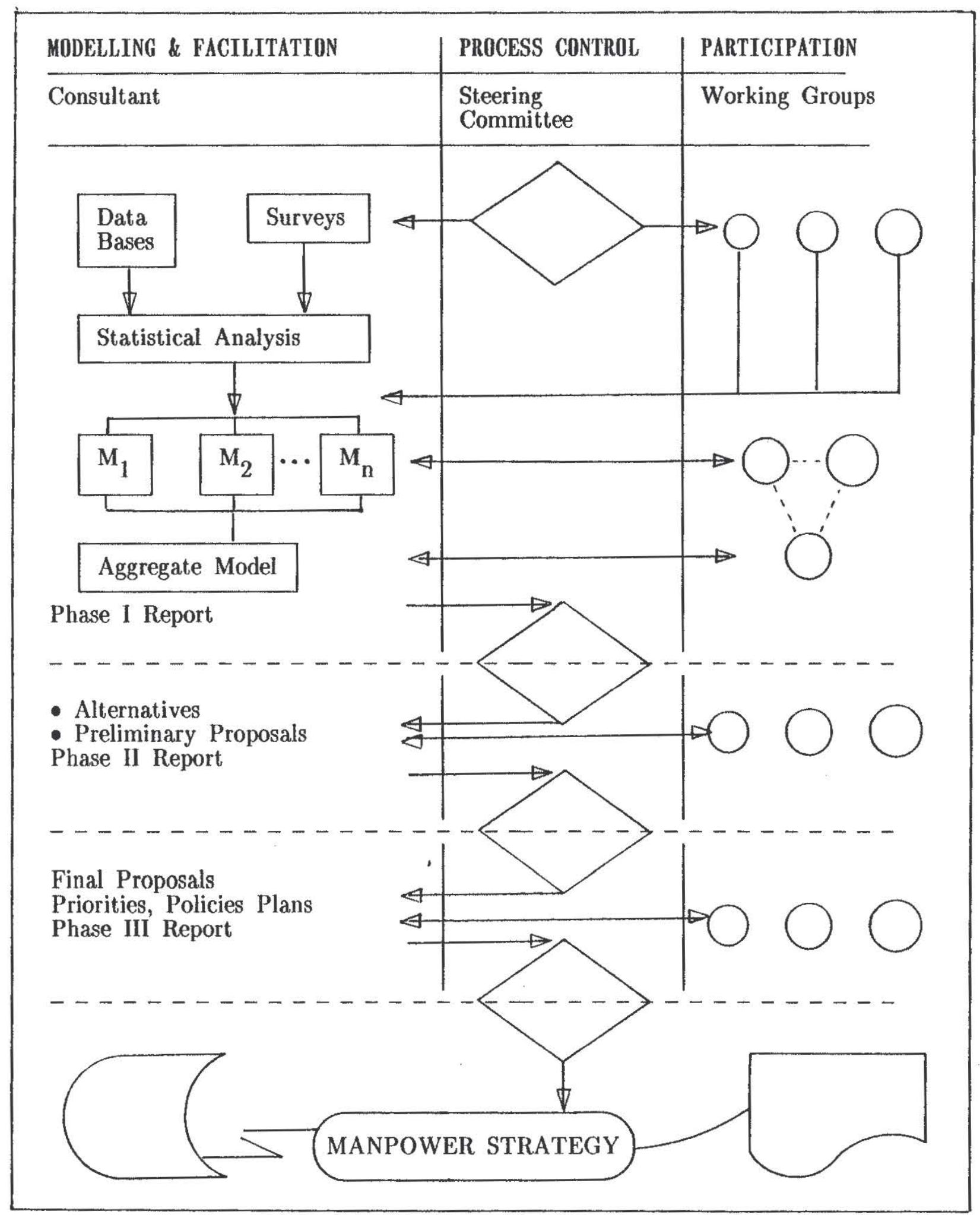

Figure 2. The Process for Manpower Planning 
fact, it serves to link the demand and supply models together since, although they are depicted as separate in the figure, they must in practice necessarily be linked. To be specific the economic model cannot function without knowledge of manpower that can be supplied by the education and training system. The production of the latter is in turn mediated by, for example, the number of teachers which is determined, in part, by the social need model.

\subsection{A Model for the Demand of Manpower}

This in fact is a synthesis of two models, each of which puts emphasis on a different perspective of manpower demand, at the same time taking into account the effects of the external environment.

\section{(i) The Economic Model}

This model is designed to forecast future manpower development on the basis of expected growth in the economy (and not on growth in population). Ultimately this indicates the manpower needs of the economy, assuming economic growth at a specified rate materializes. In order to implement this model a careful analysis must be done of the total number of workers within each occupation group in each economic sector, as far as possible by education level. It is likely that surveys will have to be undertaken to obtain adequate data for this purpose. Data on unemployment and migratory labour will also have to be included in so far as they influence the model. Other important data for this model is the contribution of each economic sector to GDP, as well as the historical and anticipated growth in the GDP and changes in the underlying structure. Note that there are alternative mathematical representations for an economic model with the abovementioned characteristics. Due consideration must be given to which is best suited to the particular application.

\section{(ii) The Social Need Model}

In contrast to the previous model, where essentially the manpower is prescribed by economic growth, the social need model is based on a normative or value approach. 
The model describes what society is likely to consider the numbers of workers, who render socially important services, ought to be in the future. Thus it gives an indication of the ideal situation, if attainable, that society demands. It is particularly relevant in the case of teachers, lecturers and health service officers. The model assumes that certain basic ratios, between the numbers of such workers and the total population, exist (based on current values for other parts of Southern Africa). Guidance from the authorities is required on this point. It can be expected that what this model will yield is a measure of the shortage of certain occupation groups relative to a standard.

\subsection{A Model for the Supply of Manpower}

The current and future potential of the existing education and training systems and facilities to deliver trained manpower at different levels must be described and incorporated into a dynamic flow model, along with the attrition of existing manpower and the influx of manpower from outside the system. As explained above this model cannot function in isolation but is dependent on output from the demographic model, and through it even from the demand model.

\subsection{Labour Flux Across the Region's Boundaries}

Of particular importance in the Southern African context is the proper consideration of migrant labour. Most statistics on countries are based on the de facto population of the country and according to internationally accepted definitions, the de facto population of a country includes all persons physically present in that country at the reference date. In terms of this definition, therefore, migrants and others temporarily absent from the country, are excluded from the de facto population. It is, however, of prime importance that they be included for many considerations, especially those relating to employment in regions where there is a significant one-way flux of labour.

There are principly three forms of labour flux relevant to this study viz 
(i) Migrant workers who work and live on a semi-permanent basis outside the region, but still contribute financially towards households in the region,

(ii) Commuters, who live in the region but work outside, and

(iii) Seasonal migrant labourers who work outside the region on a seasonal basis.

One of the major problems encountered is the estimation of the migrant work force. Since the flux of labour across the boundary is one of the key parameters in our systems approach it is imperative that this be accurately estimated. As far as we can determine most other studies fail at this point. However, a careful analysis of the different sources of data available (i.e. census data, market surveys, etc) and particularly by cross-comparison, reveals that this parameter, and other related key parameters, are in fact hidden in the raw data. In brief a set of simultaneous equations can be set up for these parameters and solved using census and other data as input. We are confident that our approach in this respect is the most reliable and accurate to date.

\section{The Development of Strategic Alternatives}

Armed with the systems model the development of strategic alternatives can be systematically and thoroughly undertaken. For each aspect a range of alternative scenarios can be generated, each based on different underlying assumptions formulated in co-operation with work groups well-acquainted with the region. In this way consideration can be given to factors such as population and economic growth, policies influencing manpower (e.g. job creation, housing, economic and sectoral development, etc), structural changes, external influences, societal aspirations, provision of education and training facilities, and so forth. By examining those sets of scenarios which lead to a balance in the demand and supply, or not, the following points, can be thoroughly investigated: 
* Imbalances, shortfalls or oversupply in particular fields of labour and the likely consequences.

* Migration trends and the impact on demand and supply.

* Shortcomings or problems with the current education and training systems and consequent implications, requirements or priorities for future policies and provisions.

* Maximising socio-economic benefits in the most cost effective manner and defining policy formulation and/or adjustments required.

* Defining facility requirements to ensure a balance between the development of new facilities and the upgrading and improved utilization of existing facilities.

* Calculating financial implications and defining a financial planning and management system to ensure ongoing success of the plan.

* Identifying required structural and/or institutional adjustments.

* Specifying an information system which can in future be used on an ongoing basis for the review of manpower planning activities.

\section{Formulation of an Overall Manpower Development Strategy}

Once the authorities have opted for one of the alternatives, or possibly some combination of several alternatives presented to them, this will have to be made explicit in terms of specific plans of action. It is more than likely that even at this late stage, as a result of new insights or suggestions, that aspects of the earlier analysis will have to be reconsidered and the model rerun in order to meet criteria such as "maximising socio-economic benefits subject to cost constraints." In particular the importance of devising "robust" plans must be emphasized - that is plans which are relatively insensitive to the variations in alternative scenarios. 
The strategy must be defined in terms of longer term strategic plans, medium term tactical plans and short term operational plans. These should include, at least a detailed statement of:

* Policy formulation/adjustment required.

* Detailed list of prioritized manpower needs.

* Institutional/Structural adjustments required.

* Facility requirements.

* Identification of projects, project linkages, phasing and financial implications.

* Structures required for the implementation and maintenance of the strategy.

* Procedures and requirements for updating a data base for monitoring the strategy.

The latter two points are particularly important since ultimately a strategy devised but not implemented is a failure. Furthermore, as projects are implemented the feedback from problems (or possibly even successes greater than those anticipated) must necessarily affect the overall strategy, requiring a revision thereof. In other words it is essential that as far as possible a comprehensive holistic and on-going approach towards the formulation and implementation of manpower planning be adopted. If this is not done many plans will at best be inadequate and the resources employed may, in the worst case, be altogether needlessly spent.

\section{The Advantages of Strategic Manpower Planning}

Although the advantages of devising a well-conceived regional manpower development strategy should be self evident the general lack of such plans in Southern Africa indicate that it is worth emphasizing the following: 
(i) In the first place a well-formulated manpower development strategy provides an essential instrument to support decision-making in respect of all facets of manpower planning in the future.

(ii) More specifically it is the vital element which is required to ensure the economic application of current resources and facilities, and of the future development of new ones.

(iii) It helps to ensure that economic development projects and the development of manpower occurs in concert and that the one fully supplements the other. This, inter alia, includes the integration of the objectives of the education and training systems at all levels.

(iv) It must be stressed that the outcome envisaged is not a static document which is formulated once and for all. Although specific plans will indeed be formulated the full strategy involves the monitoring of implementation. Along with the envisaged data base this allows for dynamic adaptation of future plans to meet changing requirements.

(v) It allows for an understanding of the factors which play a critical role in unemployment and therefore permit plans to be formulated which can at least limit unemployment to the extent which economic realities permit.

(vi) It takes full cognisance of the supply and demand factors which influence the geographic distribution of labour and thus allow these to be properly taken into account in specific plans aimed at encouraging (or discouraging) labour flows to or from specific areas.

(vii) The approach is essentially democratic in that it ensures the participation of stakeholders from all levels, local to regional, within the region. This should help considerably when it comes to implementation and hence contribute towards the achievement of objectives in respect of not only manpower development, but also economic and social development. 


\section{Conclusion}

In our limited experience, in the two sub-regions where we have to date applied the methodology, the approach we have described here is viable and sensible and forms a sound basis for regional manpower planning. Our proposals in these two cases are currently being implemented but only time will tell whether our confidence in the ultimate success of the strategies devised is indeed deserved. (Unfortunately since the strategies were commissioned by local regional authorities and have not yet been generally announced we are not in a position to reveal details at this stage).

In conclusion it is again emphasized that it is only by adopting a systems approach to projects of this nature, as is embodied in the proposed methodology, that realistic and consistent strategies can be proposed and designed. The systems approach is flexible and dynamic and can accommodate varying circumstances and requirements without radical changes. In particular since a manpower strategy is not a one-time exercise which determines policy indefinitely into the future, the systems model can be used to monitor and adapt current policy in the light of new developments.

Finally it is worth remarking that although the methodology as described here was developed specifically for regional manpower planning it is, we believe, applicable with only minor adaptations to any aspect of regional development planning.

\section{Acknowledgement}

While we believe that the abovementioned methodology and approach is innovative in the context of regional manpower planning and has not been described elsewhere we recognize a huge debt to many operations researchers and other systems thinkers whose work in many fields has undoubtedly influenced our thinking. In particular we would like to thank $\mathrm{Dr}$ J H Beukes, Prof A P Melck and Dr R H Venter for many fruitful discussions. Of course any errors or misconceptions that appear in this paper reflect only our own failings. 


\section{References}

[1] Bandyopadhyay R \& Datta S: Strategies for Backward-area Development : A Systems Approach. J Operational Research Society, Vol 40, 9, 1989.

[2] Beenstock, M (Ed): Modelling the Labour market, Chapman and Hall, London, 1988

[3] Burack E H \& Mathys N J : Human Resource Planning, A Pragmatic Approach to Manpower Staffing and Development. Revised 2nd Ed., Brace-Park Press, Lake Forest, 1987.

[4] Briggs V M, Jnr : Human Resource Development and the Formulation of National Economic Policy. $\mathrm{J}$ of Economic Issues, Vol XXI, 3, 1987.

[5] Development Bank of Southern Africa, Economic and Social Memorandum: Region G, 1989

[6] Farooq G M \& Mackellar F L : Demographic, Employment and Development Trends : The Need for Integrated Planning. International Labour Review, Vol 129, 3, 1990.

[7] Grinold R C \& Marshall K T : Manpower Planning Models. North Holland, New York, 1977.

[8] Halstead, D K: Statewide Planning in Higher Education. USA Department of Health, Education and Welfare, 1974

[9] Jenkins G M : The Systems Approach. J of Systems Engineering, Vol 3, 1969.

[10] King W R \& Cleland D I (Eds) : Strategic Planning and Management Handbook, Van Nostrand Company, New York, 1987. 
[11] Mangum G, Mangum S \& Macleans G : Manpower Planning in Developing Countries : Status, Criticisms and Lessons. International $\mathrm{J}$ of Manpower, Vol 8, 4, 1987.

[12] Mangum G \& Snedeker D : Manpower Planning for Local Labour Markets. Olympus Publishing Co, Salt Lake City, 1974.

[13] National Commission for Manpower Policy : Directions for a National Manpower Policy : A Report on the Proceedings of Three Regional Conferences. NCMP Special Report No 13, Washington, December 1976.

[14] National Training Board : Proceedings of the National Symposium on Manpower Development for the New South Africa, Department of Manpower, October 1991.

[15] Nkuhlu W L : Towards a More Effective Regional Development Strategy for Southern Africa. Development Southern Africa, Vol 4, 1, 1987.

[16] Smith A R (Ed) : Models of Manpower Systems. The English Universities Press Ltd, London, 1970.

[17] Venter R H: Determination of the Probable Numbers of New Graduates in the Different Occupations in the Southern African Constellation up to 2010: Main Text. Report SAPSE-120, Department of National Education, 1983

[18] Youdi R V \& Hinchliffe K (Eds): Forecasting Skilled Manpower Needs, UNESCO: International Institute for Educational Planning, 1985 